\title{
JURISDIÇÃO CONSULTIVA DA CORTE INTERAMERICANA DE DIREITOS HUMANOS: A EVOLUÇÃO INTERPRETATIVA DO CONCEITO DE ASILO E A OPINIÃO CONSULTIVA DO EQUADOR - (UMA ANÁLISE DESCOLONIALISTA)
}

\author{
INTER-AMERICAN COURT OF HUMAN RIGHTS CONSULTATIVE JURISDICTION : THE \\ INTERPRETATIVE EVOLUTION OF THE ASYLUM CONCEPT AND THE CONSULTATIVE \\ OPINION OF ECUADOR - (A DECOLONIALANALYSIS)
}

\section{Eduardo Biacchi Gomes}

Graduado em Direito pela Pontifícia Universidade Católica do Paraná, 1993. Mestrado em Direito pela Universidade Federal do Paraná (2000). Especialista em Direito Internacional pela Universidade Federal de Santa Catarina, 2001 e Doutor em Direito pela Universidade Federal do Paraná (2003). É Pós-Doutor em Estudos Culturais junto à

Universidade Federal do Rio de Janeiro, com estudos realizados na Universidade de Barcelona. Desenvolveu pesquisa na Universidade de Los Andes, Chile. Atualmente é professor-adjunto integrante do quadro da UniBrasil, Graduação e Mestrado em Direito. Professor Titular de Direito Internacional da Pontifícia Universidade Católica do

Paraná. Professor Adjunto do Curso de Direito Uninter e Professor colaborador do Mestrado em Direito da mesma instituição. E-mail: eduardobiacchigomes@gmail.com

\section{Amanda Carolina Buttendorff Rodrigues Beckers}

Advogada. Mestre em Direitos Humanos e Políticas Públicas pela Pontifícia Universidade Católica do Paraná. Especialista em Direito, Logística e Negócios Internacionais pela PUCPR. Especialista em Direito do Trabalho e Processo Trabalhista pela Uninter. Bacharel em Direito pela PUCPR. Pesquisadora do NEADI - Núcleo de Estudos Avançados de Direito Internacional e Desenvolvimento Sustentável. Membro da ANET - Academia Nacional de

Estudos Transnacionais. Secretária de Edição da Revista Diplomatize. E-mail: amandacbeckers@gmail.com

Recebido em: 17/11/2017

Aprovado em: 27/06/2019

RESUMO: O presente artigo visa abordar a questão da jurisdição consultiva da Corte Interamericana de Direitos Humanos, sob o viés da Justiça Constitucional, perpassando a questão do Descolonialismo, enquanto fenômeno que demonstra a evolução interpretativa da Corte, por meio do estudo do conceito de asilo utilizado na opinião consultiva solicitada pelo Equador. Metodologicamente o estudo tem referencial teórico e documental, vez que além de doutrina, utilizou-se também de consulta os documentos oficiais do órgão. Trata-se de pesquisa dedutiva, eis que parte da análise geral dos objetos de estudos em questão, quais sejam, o movimento descolonialista e a consequente interpretação extensiva do conceito de asilo, e a jurisdição consultiva ad Corte, para a análise especifica do caso concreto, qual seja a opinião Consultiva do Equador. Como resultado da pesquisa, tem-se a conclusão de que partindo dos pressupostos estudados, e analisando-se o caso concreto em questão, verificou-se uma evolução interpretativa dos direitos humanos por parte do Equador, que em sua solicitação de opinião consultiva, partindo de uma visão descolonialista, mormente no que tange ao conceito de asilo, levando referida e importante questão à discussão âmbito da Corte Interamericana. 
Palavras-chave: Corte Interamericana de Direitos Humanos; Direitos Humanos; Asilo; Jurisdição Consultiva; Descolonialismo.

ABSTRACT: This article aims to address the issue of consultative jurisdiction of the Inter American Court of Human Rights, under the bias of Constitutional Justice, addressing the issue of Decolonialism as a phenomenon which demonstrates the interpretative evolution of the Court, through the study of the asylum concept used in consultative opinion requested by Ecuador. Methodologically, the study has theoretical and documentary references, since in addition to doctrine, the official documents of the organ were also consulted. It is a deductive research, since it starts from the general analysis of the study objects in question, namely the decolonial movement and the consequent extensive interpretation of the asylum concept, and consultative jurisdiction ad Court, for the specific analysis of the concrete case, whichever is the Consultative opinion of Ecuador. As a result of the research, it is concluded that, starting from the assumptions studied, and analyzing the concrete case in question, there was an interpretative evolution of human rights by Ecuador, which in its request for an advisory opinion, starting with of a decolonial vision, especially with regard to the concept of asylum, leading to an important question in the discussion of the Inter-American Court.

Keywords: Inter-American Court of Human Rights; Human rights; Asylum; Consultative Jurisdiction; Decolonialism.

SUMÁRIO: Introdução. 1. Direitos Humanos em uma visão descolonialista. 2. Justiça Constitucional, Jurisdição Consultiva da CIDH e o diálogo entre jurisdições. 3. Opinião consultiva do Equador e interpretação evolutiva dos Direitos Humanos. Considerações finais. Referências.

\section{INTRODUÇÃO}

Muitas foram as modificações do âmbito do direito internacional e dos direitos humanos no período pós Segunda-Guerra Mundial. Os direitos humanos passaram a ser tema de interesse internacional, fazendo surgir uma onda de internacionalização dos documentos atinentes à temática e incutindo a ideia de que sua salvaguarda não mais seria assunto somente interno dos países.

Paralelamente, o direito internacional se viu frente a um momento de modificação de abrangência e eficácia, eis que os Estados soberanos, no exercício de suas soberanias, passaram a assumir associar-se e assumir obrigações internacionais nas mais diversas áreas de atuação, o que se consolidou com a criação da Organização das Nações Unidas - ONU.

La propia Carta de la Organización establece en su preámbulo la intención de los países signatarios de "crear condiciones bajo las cuales puedan mantenerse la justicia y el respeto a las obligaciones emanadas de los tratados y de otras fuentes del derecho internacional'. De esta forma el derecho internacional creció considerablemente durante la segunda mitad del siglo XX expandiendo su corpus juris para regular un gran número de materias, todas ellas del interés de la comunidad internacional. ${ }^{1}$.

Neste contexto, mister ressaltar que a associação dos Estados em organizações internacionais, modificou sobremaneira, o modo de encarar o direito internacional, criando o que alguns doutrinadores denominaram de justiça constitucional internacional.

${ }^{1}$ STEINER, Christian. Convención Americana sobre Derechos Humanos: comentada. Colombia:Fundación Konrad Adenauer, Programa Estado de Derecho para Latinoamérica, 2014. p.4.

Revista de Direito Brasileira | Florianólopis, SC | v. 25 | n. 10 | p. 183-199 | Jan./Abr. 2020 
Neste contexto cumpre asseverar que sob a perspectiva dos direitos humanos, existe uma estreita ligação entre a ordem jurídica internacional e a nacional, surgindo o o chamado diálogo entre jurisdições. A temática da jurisdição constitucional ganha relevo e destaque, ante a necessidade de os juízes observarem e aplicarem corretamente os tratados de direitos humanos ratificados pelos Estados, sob pena caracterizar a responsabilidade internacional.

Concretamente, em relação aos direitos humanos, âmbito das Américas, a formação da Organização dos Estados Americanos - OEA em Bogotá, criada pela chamada Carta da OEA, datada de 1948 - embora muito antes, em meados do século XIX já se houvesse notícia de um movimento entre países que visava a união dos países americanos no intuito de fomentar o desenvolvimento local e manter a paz - foi marco histórico no que tange a modificação de enfrentamento do conceito de jurisdição internacional e proteção aos direitos humanos.

Para realizar os princípios em que se baseia e para cumprir com suas obrigações regionais, de acordo com o art. $2^{\circ}$ da Carta, estabelece como propósitos essenciais os seguintes: a) garantir a paz e a segurança continentais; b) promover e consolidar a democracia representativa, respeitado o princípio da não intervenção; e) prevenir as possíveis causas de dificuldades e assegurar a solução pacífica das controvérsias que surjam entre seus membros; d) organizar a ação solidária destes em caso de agressão; e) procurar a solução dos problemas políticos, jurídicos e econômicos que surgirem entre os Estados-membros; f) promover, por meio da ação cooperativa, seu desenvolvimento econômico, social e cultural; g) erradicar a pobreza crítica, que constitui um obstáculo ao pleno desenvolvimento democrático dos povos do Hemisfério; e h) alcançar uma efetiva limitação de armamentos convencionais que permita dedicar a maior soma de recursos ao desenvolvimento econômico-social dos Estados-membros ${ }^{2}$.

A Declaração Americana dos Direitos e Deveres do Homem, documento que formalizou o chamado Sistema Interamericano de Proteção aos Direitos Humanos, estruturado em dois órgãos de atuação a Comissão Interamericana de Direitos Humanos e a Corte I Interamericana de Direitos Humanos, ora objeto de estudo do presente texto.

A Convenção Americana sobre Direitos Humanos, também conhecida como Pacto de San José da Costa Rica, firmada em 1969 e seus protocolos adicionais, veio a enriquecer o Sistema, reconhecendo como obrigação dos Estados da OEA o respeito e a promoção dos direitos e liberdades nela elencados

El trabajo de la Corte Interamericana se presenta como decisivo a la hora de fortalecer la defensa de los derechos fundamentales en las jurisdicciones domésticas. De este modo, los Estados que han ratificado la Convención, y más aquellos que han aceptado la competencia de la Corte, se obligan a cumplir con estos compromisos internacionales en el orden interno y a incorporar el desarrollo jurisprudencial de la Corte directamente en sus jurisdicciones nacionales. Este compromiso se ve reflejado en muchos de estos Estados que han incorporado a sus Constituciones los tratados internacionales de derechos humanos otorgándoles jerarquía constitucional ${ }^{3}$.

Não se pode olvidar, contudo, que os valores que originaram o Sistema Interamericano, têm raízes eurocêntricas, razão pela qual, se deve buscar uma interpretação extensiva e evolutiva dos direitos humanos, o que conforme se verá adiante, já tem sido explorada pela Corte em sua

\footnotetext{
${ }^{2}$ MAZZUOLI, Valério de Oliveira. Curso de direito internacional público. 9. ed. rev., atual. e ampl. -- São Paulo: Editora Revista dos Tribunais, 2015. p. 722.

${ }^{3}$ STEINER, Christian. Convención Americana sobre Derechos Humanos: comentada. Colombia: Fundación Konrad Adenauer, Programa Estado de Derecho para Latinoamérica, 2014. p.XII.

Revista de Direito Brasileira | Florianólopis, SC | v. 25 | n. 10 | p. 183-199 | Jan./Abr. 2020
} 
jurisdição consultiva, mormente no que tange as opiniões consultivas, a exemplo da Opinião Consultiva solicitada pelo Panamá, que trás uma interpretação evolutiva e bastante inovadora, compreendendo as empresas transnacionais como sujeitos de direito internacional.

A Corte Interamericana vem exercendo ao passar das décadas, um importante papel enquanto único tribunal internacional do continente a trabalhar na defesa e proteção dos direitos humanos. Sua atuação pode se dar de maneira consultiva ou contenciosa, neste último caso, tratase de ação de caráter complementar a atuação interna das Cortes dos Estados, eis que para acesso à sua jurisdição, necessário exaurimento das instâncias judiciais nacionais; é em verdade a atuação consultiva da do órgão que ora será abordada.

Referida atuação se dá mediante a interpretação e consequente orientação aos Estados no que tange à aplicação do disposto na Convenção Americana e demais tratados correlatos. Sua função precípua é dirimir duvidas quanto a interpretação da norma, evitando vícios de conduta dos Estados no que concerne ao cumprimento das obrigações contidas na Convenção, intentando prevenir conflitos e harmonizar a atuação internacional em temáticas de interesse da OEA.

Neste contexto, o objetivo central do presente estudo se volta à análise da questão da jurisdição consultiva da Corte Interamericana de Direitos Humanos, mediante o estudo de caso concreto, qual seja a solicitação de Opinião Consultiva elaborada pelo Equador, e a consequente evolução interpretativa do conceito de asilo que o documento pressupõe, a partir de uma visão descolonialista dos direitos humanos.

A metodologia utilizada para tanto, será de revisão de literatura especializada, com foco nas resoluções e na Opinião Consultiva da OEA ora abordada, no fito de compreender de que forma a organização tem entendido o problema estudado, e como se tem reconhecido a jurisdição consultiva do órgão, sob a perspectiva descolonialista proposta neste artigo.

Concretamente, o presente artigo aborda a questão da jurisdição, na exata medida em que cabe ao juiz estatal aplicar corretamente os tratados de direitos humanos. Vale destacar que a atuação da Corte Interamericana de Direitos Humanos é subsidiária, isto é, em primeira instância e de acordo com os artigos $1^{\circ}$ e $2^{\circ}$ do Pacto de San José da Costa Rica, é dever do Estado cumprir com os direitos previstos naquele tratado e, consequentemente, aplicar e implementar dentro de seu ordenamento jurídico. Ou seja: o controle jurisdicional deverá ser realizado pelo juiz nacional.

Todavia, uma análise sistêmica da matéria, torna-se importante para uma maior reflexão e compreensão dos direitos humanos dentro da América Latina.

\section{DIREITOS HUMANOS EM UMA VISÃO DESCOLONIALISTA}

Tida pela corrente a qual filia-se Anibal Quijano como a 'primeira identidade da modernidade', verdadeiro espaço de poder, a América enfrenta a beleza e a dificuldade de tratar direitos humanos por uma visão descolonialista. Os processos históricos precedentes - de um lado as diferenças entre conquistadores e imposta e suposta distinção da ideia de raça causando uma subsunção do colonizado ao colonizador; de outro, as formas de controle de trabalho, recursos e capital, em torno de um eixo eurocêntrico de poder ${ }^{4}$ - são fatores de impacto que tange a interpretação que se faz do processo de luta pelos direitos humanos latino-americanos.

$\mathrm{Na}$ América, a ideia de raça foi uma maneira de outorgar legitimidade às relações de dominação impostas pela conquista. A posterior constituição da Europa como nova identidade depois da América e a expansão do colonialismo europeu ao resto do mundo conduziram à elaboração da perspectiva eurocêntrica do conhecimento e com ela à elaboração teórica da ideia de raça como naturalização dessas relações

\footnotetext{
${ }^{4}$ QUIJANO, Anibal. Colonialidade do poder, Eurocentrismo e América Latina. In.: A colonialidade do saber: eurocentrismo e ciências sociais. Perspectivas latino-americanas. CLACSO, Consejo Latinoamericano de Ciencias Sociales, Buenos Aires: 2005. p.117.
}

Revista de Direito Brasileira | Florianólopis, SC | v. 25 | n. 10 | p. 183-199 | Jan./Abr. 2020 
coloniais de dominação entre europeus e não-europeus. Historicamente, isso significou uma nova maneira de legitimar as já antigas ideias e práticas de relações de superioridade/inferioridade entre dominantes e dominados. Desde então demonstrou ser o mais eficaz e durável instrumento de dominação social universal ${ }^{5}$.

Este fenômeno eurocêntrico de dominação, até hoje enraizado por todo mundo ocidental transformou-se em verdadeiro instrumento de dominação ${ }^{6}$, dificultando sobremaneira o reconhecimento e o resgate da identidade americana, e suas consequentes lutas sociais, mascarando assim por séculos, a construção latino-americana por direitos humanos de e para americanos.

Para tratar de uma descolonização dos direitos humanos é importante ter em vista que os direitos humanos são construídos historicamente e dentro da história, quer dizer, eles são respostas às necessidades de determinados contextos históricos e, no momento que assumidos como históricos, passam a fazer parte da História, não como movimento linear, mas pautado pelas relações de poder. Esta forma de entender os direitos humanos como históricos alcança a pretensão de torná-los como instrumentos universais de luta daquelas pessoas que estão à margem dos próprios direitos humanos, pois sem esta perspectiva tende-se a torná-los um discurso de docilidade, domesticação e de legitimação de um sistema econômicosocial excludente ${ }^{7}$.

Há que se ponderar que a teoria da existência das elites jurídicas, nas quais há diferentes modos de e aplicar o direito, considerando as diferenças dos sujeitos e as relações de poderes envolvidos, o que Enrique Dussel denomina de 'qualidade ad extra da modernidade eurocêntrica', "na qual a violência tem caráter de sagrada, pois parte da emancipação do/a outro/a, mesmo que seja impetrada pela força" ${ }^{8 "}$.

Veja-se que "é possível perceber que os direitos humanos concebidos enquanto universais deixam de cumprir com sua função de construção de uma realidade pautada pela justiça e equidade no instante em que se afasta do contexto das pessoas ${ }^{9 "}$, em um modelo estático eurocentrista que não acompanha o caminhar da construção dos direitos enquanto lutas sociais.

Na mesma linha, Boaventura de Souza Santos trabalha com a ideia de 'outro lado da linha', na qual aqueles que estão do lado mais fraco são relegados ao esquecimento e a invisibilidade, sendo uma característica deste pensamento dito abissal, a impossibilidade de coexistência de ambos os $\operatorname{lados}^{10}$.

\footnotetext{
${ }^{5}$ QUIJANO, Anibal. Colonialidade do poder, Eurocentrismo e América Latina. In.: A colonialidade do saber: eurocentrismo e ciências sociais. Perspectivas latino-americanas. CLACSO, Consejo Latinoamericano de Ciencias Sociales, Buenos Aires: 2005. p.118.

${ }^{6}$ QUIJANO, Anibal. Colonialidade do poder, Eurocentrismo e América Latina. In.: A colonialidade do saber: eurocentrismo e ciências sociais. Perspectivas latino-americanas. CLACSO, Consejo Latinoamericano de Ciencias Sociales, Buenos Aires: 2005. p.118.

7 STRELHOW, Thyeles Moratti Precilio Borcarte. Direitos humanos: reflexões por um processo de descolonização. Revista Interdisciplinar de Direitos Humanos. Bauru, v. 4, n. 2, p. 59-76, jul./dez., 2016 (7). Disponível em: < http://www2.faac.unesp.br/ridh/index.php/ridh/article/view/389 > Acesso em 25 jun. 2017. p.67.

${ }^{8}$ DUSSEL, Enrique. Europa, modernidade e eurocentrismo. In: LANDER, Edgardo. A colonialidade do saber: eurocentrismo e ciências sociais. Perspectivas latino-americanas. Colecci- ón Sur Sur. CLACSO: Buenos Aires: 2005, p. 29.

${ }^{9}$ STRELHOW, Thyeles Moratti Precilio Borcarte . Direitos humanos: reflexões por um processo de descolonização. Revista Interdisciplinar de Direitos Humanos. Bauru, v. 4, n. 2, p. 59-76, jul./dez., 2016 (7). Disponível em: < http://www2.faac.unesp.br/ridh/index.php/ridh/article/view/389 > Acesso em 25 jun. 2017. p.66.

${ }^{10}$ SANTOS, Boaventura de Sousa. Para além do pensamento abissal: das linhas globais a uma ecologia de saberes. Novos Estudos, n. 79. 2007. Disponível em: < http://www. scielo.br/pdf/nec/n79/04.pdf > Acesso em 12 jul. 2017. p. 91.
} 
O autor entende "deste lado da linha" o pensamento eurocêntrico, do qual, sistematicamente os direitos humanos foram alocados. É bastante significativo que uma das dificuldades de alcançar os direitos humanos a todas as pessoas esteja ligado à esta construção abissal que concebe o/a outro/a "do outro lado da linha" a partir do paradigma da "apropriação e violência", ao contrário do que se compreende, a partir da eurocentricidade, para os humanos "deste lado da linha", regulação e emancipação social ${ }^{11}$.

É certo que se os direitos humanos são lutas sociais, percurso a ser trilhado e não meta a ser alcançada, eis que a transformação social é diuturna, não se pode construir direitos humanos na Américalatina eu uma base eurocêntrica, chegando-se ao ponto de discussão que até hoje permeia a doutrina internacional, sobre o universalismo dos direitos humanos, em seu caráter ocidental ${ }^{12}$. Problema que Boaventura enfrenta com sua teoria sobre localismo globalizado e o cosmopolitismo insurgente.

Há ainda outras interessantes linhas de raciocínio que analisam o fenômeno descolonialista na América-latina, com o viés da modernidade e da contra-modernidade, capitaneadas inclusive por Quijano e Dussel e tantas outras teorias não menos importantes a reflexão do tema, que não serão objeto do presente estudo, que se dispõe a uma reflexão breve sobre a temática e suas refrações no tema central do mesmo, qual seja, a jurisdição consultiva da Corte Interamericana de Direitos Humanos.

Nesta toada, há que se ponderar que a implementação do Sistema Americano de Proteção aos Direitos Humanos foi sem dúvida um importante passo para a proteção dos direitos humanos em sua visão descolonialista, mormente, por levar em consideração em sua atuação, a realidade social dos países americanos, postura que foi verificada inicialmente com o caso Mayagna Vs. Nicarágua, datado de 2001, na qual a Corte "passou a apreciar e julgar vários casos de violação de direitos cuja titularidade corresponde a coletividades diferenciadas étnico-culturalmente, sobretudo povos indígenas e comunidades quilombolas ${ }^{13}$ ".

Verifica-se a atenção ao povos tradicionais e a base descolonialista adotada pela Corte no caso em análise, "Não somente é dada ampla oportunidade de manifestações orais perante os juízes da Corte, mas os discursos produzidos são auxiliados por documentos referentes a estudos etnográficos sobre a comunidade indígena, o que em ambos os casos provoca o efeito de introduzir no contexto simbólico do processo a identificação dos autores como grupo étnico-cultural diferenciado, cuja diferença é constantemente revisitada ao longo das narrativas e produções textuais nos diversos aspectos da vida social, desde a história de origem e migração da comunidade, passando pela constituição identitária, organização social, direito consuetudinário, até chegar ao ápice da construção diferenciada do território e da propriedade ${ }^{14}$.

Desde então, tem-se verificado o uma especial atenção à questão da descolonialidade na atuação da Corte, que segundo parte da doutrina, tem demonstrado ativismo político-jurídico em relação aos direitos humanos, adotando metodologia interpretativa, pautada pelos critérios da:

\footnotetext{
${ }^{11}$ STRELHOW, Thyeles Moratti Precilio Borcarte . Direitos humanos: reflexões por um processo de descolonização. Revista Interdisciplinar de Direitos Humanos. Bauru, v. 4, n. 2, p. 59-76, jul./dez., 2016 (7). Disponível em: < http://www2.faac.unesp.br/ridh/index.php/ridh/article/view/389 > Acesso em 25 jun. 2017. p.67.

${ }^{12}$ Mais sobre o assunto em: SANTOS, Boaventura de Sousa. Descolonizar el saber, reinventar el poder. Ediciones Trilce, Montevidéu: 1988. p.67 e seguintes.

${ }^{13}$ OLIVEIRA, Assis da Costa. Pós-Colonialismo, Relações Internacionais E Direitos Humanos: Análise Do Caso Mayagna (Sumo) Awas Tingni Vs. Estado Da Nicarágua. O Direito Alternativo, v.2, n.1, pp. 39-63, junho de 2013. p.48.

${ }^{14}$ OLIVEIRA, Assis da Costa. Pós-Colonialismo, Relações Internacionais E Direitos Humanos: Análise Do Caso Mayagna (Sumo) Awas Tingni Vs. Estado Da Nicarágua. O Direito Alternativo, v.2, n.1, pp. 39-63, junho de 2013. p.52/53.
} 
(1) polissemia dos termos jurídicos: os termos jurídicos empregados na redação de um instrumento de direitos humanos têm significado, sentido e alcance "autônomos", não equiparáveis aos que esses termos podem ter no direito interno; (2) instrumentos de direitos humanos como instrumentos vivos: vivacidade no sentido de dever de interpretação dos instrumentos jurídicos de maneira que concorde com as transformações das condições de vida; (3) integração do corpo jurídico do direito internacional dos direitos humanos: sendo útil e apropriado utilizar outros tratados internacionais de direitos humanos distintos da Convenção Americana, a fim de considerar a questão sujeita a exame no quadro da progressividade da interpretação dos direitos humanos ${ }^{15}$.

É, e com esta abordagem, de ativismo político, não só no que tange aos direitos dos povos tradicionais, mas também à questões transversais, que se tem verificado a atuação da Corte Interamericana de Direitos Humanos, mormente no que tange a uma interpretação evolutiva os direitos humanos.

Referido posicionamento, se dá em grande parte, no que tange ao tema ora estudado, a interpretação extensiva do conceito de refúgio, pelo disposto na Declaração de Cartagena - 1984, que visou desvincular o conceito de asilo de sua base eurocêntrica, levando em consideração as especificidades latino-americanas em tal enquadramento.

De outro lado, o conceito latino-americano de asilo, firmado do Tratado de Direito Penal Internacional de Montevidéu, de 1889, e oriundo da VI Conferência Pan-americana de Havana de 1928, a qual dispôs sobre a possibilidade de concessão de asilo diplomático, instituto tido como característico $^{16}$ da América Latina.

Nesta toada, tem-se que "a interpretação convergente dos institutos do asilo e do refúgio possibilitou a superação da interpretação conservadora fundada na colonialidade do poder ${ }^{17}$ ". Fator importante para a efetivação de uma visão descolonialista dos institutos e sua aplicação pela Corte Interamericana de Direitos Humanos.

\section{JUSTIÇA CONSTITUCIONAL, JURISDIÇÃO CONSULTIVA DA CIDH E O DIÁLOGO ENTRE JURISDIÇÕES}

Inicialmente há que se ponderar sobre a atual conjuntura do Estado-nação moderno e a justiça constitucional - "o poder constituinte é um poder anterior ao direito positivo, pois o escopo da capacidade de se fazer uma Constituição é, com a Constituição, inaugurar a cadeia hierárquica normativa de um Estado e/ou da Cosmópolis (no caso do constitucionalismo mundial) ${ }^{18}$ " - no que tange aos direitos humanos e documentos internacionais atinentes à temática.

A questão do cosmopolitismo e da assunção de problemas globais em detrimento de questões locais, tem se mostrado cada vez mais latente no cenário do direito.

\footnotetext{
${ }^{15}$ OLIVEIRA, Assis da Costa. Pós-Colonialismo, Relações Internacionais E Direitos Humanos: Análise Do Caso Mayagna (Sumo) Awas Tingni Vs. Estado Da Nicarágua. O Direito Alternativo, v.2, n.1, pp. 39-63, junho de 2013. p.54.

${ }^{16}$ BRASIL. Justiça e Segurança Pública. Disponível em: < http://www.justica.gov.br/noticias/entenda-as-diferencasentre-refugio-e-asilo > Acesso em 01 set. 2017.

17 BAPTISTELA, Tiago. A integração e a convergência do asilo e do refugio na Declaração de Cartagena. (mestrado em direito) Santa Maria, 2016. p.66.

${ }^{18}$ PAGLIARINI, Alexandre Coutinho. Direito Constitucional Internacional, Reforma Das Nações Unidas E Corte Constitucional Internacional. Revista Ajuris. Revista da AJURIS - Porto Alegre, v. 43, n. 141, Dezembro, 2016. Disponível em: < http://www.ajuris.org.br/OJS2/index.php/REVAJURIS/article/view/620 > Acesso em 13 set. 2017.p.55
} 
O poder constituinte implica a feitura de uma Constituição; uma Constituição implica a estruturação da Pólis e/ou da Cosmópolis e a proclamação de direitos fundamentais; a soberania implica a crença no Estado delimitado territorialmente, com um governo superior e regras respeitadas, o que, por sua vez, implica o Estado-nação da modernidade ${ }^{19}$.

No âmbito dos direitos humanos - "reconhecer os direitos e lutar por sua adequada proteção torna-se um elemento catalisador das aspirações democráticas. Desta forma a Justiça Constitucional, pelo controle de constitucionalidade das leis, pode avocar para si o papel de tutora dos referidos direitos, permitindo a instituição e a promoção dos ideais democráticos" 20 pode-se considerar que o combate à violação de tais direitos e sua consequente preservação ${ }^{21}$, é tema de interesse da justiça constitucional internacional.

Nesse aspecto a Justiça Constitucional, agindo em defesa do valor dos preceitos constitucionais, representa a garantia de proteção ao cidadão contra eventuais violações aos direitos inerentes a sua sobrevivência, atuando como remédio de defesa e luta para a concretização dos direitos fundamentais, sendo tecnicamente hábil para protegê-los, quando no controle preventivo, e para restaurá-los, quando em atuação posterior a sua violação ${ }^{22}$.

De mesma forma pode-se interpretar a atuação da Corte Interamericana de Direitos Humanos, que tem jurisdição para de manifestar sobre violações de direitos humanos de qualquer pessoa sujeita à sua jurisdição ${ }^{23}$, independentemente da nacionalidade da vitima, "bastando que o cidadão tenha sido violado em seus direitos no âmbito da jurisdição de um Estado parte na Convenção Americana (que tenha aceitado a jurisdição contenciosa da Corte Interamericana) ${ }^{24}$ ".

La Corte Interamericana ha establecido que los Estados pueden consultarle sobre cualquier norma de derecho interno: leyes, proyectos de ley, la Constitución vigente y los proyectos de reforma constitucional. En ese sentido, la propuesta está dirigida a que la Corte Interamericana pueda pronunciarse, a solicitud de los tribunales de cierre de los ordenamientos nacionales, sobre la compatibilidad de una norma constitucional con la Convención Americana u otros tratados internacionales que tengan relación con la protección de los derechos humanos.

19 PAGLIARINI, Alexandre Coutinho. Direito Constitucional Internacional, Reforma Das Nações Unidas E Corte Constitucional Internacional. Revista Ajuris. Revista da AJURIS - Porto Alegre, v. 43, n. 141, Dezembro, 2016. Disponível em: < http://www.ajuris.org.br/OJS2/index.php/REVAJURIS/article/view/620 > Acesso em 13 set. 2017. p. 56.

${ }^{20}$ BRAGHIROLLI, Fernanda. Justiça Constitucional: a Forma Garantidora do Estado Democrático de Direito e sua Necessária Intervenção na Busca da Concretização dos Direitos Fundamentais. no X V I I no 29, j an .- jun. 200 8. p. 100.

${ }^{22}$ BRAGHIROLLI, Fernanda. Justiça Constitucional: a Forma Garantidora do Estado Democrático de Direito e sua Necessária Intervenção na Busca da Concretização dos Direitos Fundamentais. no X V I I n ${ }^{\circ}$ 29, j an .- j un. 200 8. p. 100.

${ }^{23}$ Vejamos o disposto na Opinião Consutiva 1, de 24 de setembro de 1982, solicitada pelo Peru: "la competencia consultiva de la Corte puede ejercerse, en general, sobre toda disposición, concerniete a la protección de los derechos humanos, de cualquier tratado internacional aplicable ne los Estados americanos, com independencia de que sea bilateral o multilateral, de cuál sea su objeto principal o de que sean o puedan ser partes del mismo Estados ajenos al sistema interameriano. CORTE INTERAMERICANA DE DIREITOS HUMANOS. Parecer consultivo solicitado pelo Peru - Opinião Consutiva 1 , de 24 de setembro de 1982. Disponível em: < http://www.corteidh.or.cr/cf/Jurisprudencia2/solicitud_opiniones_consultivas.cfm?lang=es > Aceso em 07 jul. 2017.

${ }^{24}$ MAZZUOLI, Valério de Oliveira. Curso de direito internacional público. 9. ed. rev., atual. e ampl. São Paulo: Editora Revista dos Tribunais, 2015. p.983.

Revista de Direito Brasileira | Florianólopis, SC | v. 25 | n. 10 | p. 183-199 | Jan./Abr. 2020 
A jurisdição da Corte poderá se dar de forma contenciosa e também consultiva, que ora nos interessa. "La competencia consultiva está regulada en el Pacto de San José, en el Reglamento y en el Estatuto, y tiene en miras según lo ha expresado el mencionado Tribunal - coadyuvar al cumplimiento de las obligaciones internacionales de los Estados ${ }^{25}$ ".

Neste sentido, a interpretação consultiva dos pareceres, que embora não possuam caráter obrigatório, podem servir como importante marco jurídico, verdadeiro suporte para os Estados interpretarem tratados de direitos humanos, proporcionando um diálogo de jurisdições.

De acordo com o disposto nos artigos 1. e 2. de seu Estatuto, a Corte Interamericana possui duas atribuições essenciais: a primeira, de natureza consultiva, relativa à interpretação das disposições da Convenção Americana, assim como das disposições concernentes à proteção dos direitos humanos nos Estados Americanos; a segunda, de caráter jurisdicional, referente à solução de controvérsias que se apresentem acerca da interpretação ou aplicação da própria Convenção ${ }^{26}$.

Qualquer membro da OEA, sendo parte ou não da Convenção, pode invocar a Corte no tocante a interpretação de tratado de direitos humanos no âmbito dos Estados Americanos.

A Corte tem exercido sua jurisdição consultiva no sentido de realizar importantes contribuições conceituais no campo do direito internacional dos direitos humanos. Por meio de sua jurisdição consultiva, a Corte tem contribuído para conferir uniformidade e consistência à interpretação de previsões substantivas e procedimentos da Convenção Americana e de outros tratados de direitos humanos ${ }^{27}$.

A Corte fornecerá parecer consultivo sobre o tema, podendo ainda traçar comentários sobre a compatibilidade da lei doméstica invocada com outras disposições de instrumentos internacionais.

"A competência consultiva da Corte, esta é aberta a todos os Estados-membros da OEA, ainda que não tenham ratificado a Convenção Americana de Direitos Humanos. Pode ser exercida a competência consultiva para o esclarecimento de questões atinentes à interpretação da Convenção, bem com de outros documentos dos Estados Americanos referentes à Proteção dos Direitos Humanos. ${ }^{28}$.

No que tange a questão da internalização das disposições (sentenças e opiniões consultivas) da Corte Interamericana de Direitos Humanos, necessário observar o Regulamento Interno da CIDH e mesmo a jurisprudência do órgão, a fim de que haja uma uniformização do padrão interpretativo sobre o disposto na Convenção, com o fito de proporcionar não só a efetiva salvaguarda aos direitos humanos, mas também maior segurança jurídica no que tange a aplicação da norma internacional.

No que tange ao efeito condenatório propriamente dito, por certo que a sentença, para o terceiro Estado, vale como res inter alios acta. Porém, no que tange a vários

\footnotetext{
${ }^{25}$ HITTERS, Juan Carlos. Son vinculantes los pronunciamentos de la Comisión y de la Corte Interamericana de Derechos Humanos? Revista Iberoamericana de Derecho Procesal Constitucional. núm. 10, julio-diciembre 2008, pp. 131-156.p. 148.

${ }^{26}$ PIOVESAN, Flávia. Direitos Humanos e Justiça Internacional. São Paulo: Saraiva, 2006. p. 99.

${ }^{27}$ JAYME, Fernando G. Direitos Humanos e sua efetivação pela Corte Interamericana de Direitos Humanos. Belo Horizonte: Del Rey, 2005. p.94.

${ }^{28}$ SANTOS, Alberto da Silva. O Sistema Interamericano de proteção aos Direitos Humanos e a soberania Estatal. Dissertação de Mestrado. PUCPR, 2010. p.112.
}

Revista de Direito Brasileira | Florianólopis, SC | v. 25 | n. 10 | p. 183-199 | Jan./Abr. 2020 
outros efeitos, como (especialmente) o relativo à interpretação que faz a Corte da Convenção Americana, pode-se afirmar que os terceiros Estados têm o dever de abster-se de aplicar ou interpretar o seu Direito interno em desacordo com a interpretação acolhida pela Corte de San José. Quando um órgão do Estado (v.g. , o Poder Judiciário) assim não procede e decide na contramão dos ditames internacionais, abre para o Estado em causa a possibilidade de ser condenado pela Corte num caso concreto semelhante que venha a ocorrer no futuro. Assim, podese dizer que a sentença da Corte Interamericana vincula indiretamente (com caráter erga omnes) todos os terceiros Estados, valendo como res interpretata a ser seguida no direito interno ${ }^{29}$.

As sentenças dos casos contenciosos, bem como as opiniões consultivas deveria "deveriam ter eficácia interpretativa erga omnes, vinculando terceiros Estados à interpretação que realiza a Corte sobre o alcance e o conteúdo de um dispositivo convencional", vide artigos 70 a 72 do Regulamento da Corre Interamericana de Direitos Humanos.

Veja-se que esta incorporação deve se dar de forma ampliativa aos direitos já consagrados no direito interno, em atenção ao princípio pro homine, preconizado na alínea b, artigo 29 da Convenção Americana, que prevê que "nenhuma disposição da Convenção pode ser interpretada no sentido de limitar o gozo e exercício de qualquer direito ou liberdade que possam ser reconhecidos em virtude de leis de qualquer dos Estados-partes ou em virtude de Convenções em que seja parte um dos referidos Estados".

Puede decirse —en suma- que no obstante que tales opiniones no son obligatorias en sentido estricto, su fuerza radica en la autoridad moral y científica de la Corte y si bien su esencia es típicamente asesora, no por ello deja de ser jurisdiccional, y tiene por objeto coadyuvar al cumplimiento de las obligaciones internacionales de los estados americanos, en lo que concierne a la protección de los derechos humanos ${ }^{30}$.

Cabe destacar que o já citado diálogo de jurisdições tem se mostrado importante instrumento de interpretação dos direitos humanos. Referido diálogo se mostra imprescindível para fomentar a discussão de uma visão descolonialista dos direitos humanos e efetivar uma implementação eficaz nos Estados, das opiniões consultivas e sentenças da Corte Interamericana.

As Constituições latino-americanas estabelecem cláusulas constitucionais abertas, que permitem a integração entre a ordem constitucional e a ordem internacional, especialmente no campo dos direitos humanos, ampliando e expandindo o bloco de constitucionalidade ${ }^{31}$.

Mister ressaltar a importância do controle de convencionalidade e do diálogo de jurisdições entre os documentos e as decisões internacionais sobre direitos humanos e o ordenamento jurídico interno dos Estados.

"É neste contexto - marcado pela tendência de Constituições latino-americanas em assegurar um tratamento especial e diferenciado aos direitos e garantias

\footnotetext{
${ }^{29}$ MAZZUOLI, Valério de Oliveira. Curso de direitos humanos. 9. ed. rev., atual. e ampl. São Paulo: Método, 2014. p.44.

${ }^{30}$ HITTERS, Juan Carlos. Son vinculantes los pronunciamentos de la Comisión y de la Corte Interamericana de Derechos Humanos? Revista Iberoamericana de Derecho Procesal Constitucional. núm. 10, julio-diciembre 2008, pp. 131-156. p. 149.

${ }^{31}$ PIOVESAN, Flávia. Direitos humanos e diálogo entre jurisdições. Revista Brasileira de Direito Constitucional - RBDC. n. 19 - jan./jun. 2012 Disponível em: < http://www.esdc.com.br/seer/index.php/rbdc/article/view/176/170 > Acesso em 17 set. 2017. p.69.
}

Revista de Direito Brasileira | Florianólopis, SC | v. 25 | n. 10 | p. 183-199 | Jan./Abr. 2020 
internacionalmente consagrados — que se insere o desafio de encorajar todos os textos constitucionais latino-americanos a incluírem cláusulas abertas a conferir aos tratados de direitos humanos status hierárquico constitucional ${ }^{32}$ ".

Verifica-se que a necessidade de observância às decisões é corroborada pela própria jurisprudência internacional da Corte, a qual deve ser observada sempre na interpretação da salvaguarda dos direitos humanos.

Segundo a jurisprudência reiterada da Corte lnteramericana, as autoridades do Estado têm a obrigação não só de aplicar a Convenção Americana, bem assim de aplicá-la tal como interpretada pela Corte de San José. Isso significa que os juízes e tribunais dos Estados-partes à Convenção Americana devem aplicar tanto a Convenção como a jurisprudência que sobre ela se formar no seio da Corte lnteramericana, quer ou não as decisões desta última lhes sejam diretamente dirigidas; todos os terceiros Estados devem (não se trata de uma faculdade, mas de uma obrigação erga omnes) aplicar a Convenção e a jurisprudência da Corte Interamericana no plano do direito interno, em homenagem ao exercício do controle de convencionalidade lato sensu ${ }^{33}$.

Não se pode olvidar, que embora não tenha oficialmente caráter vinculante, a jurisdição consultiva visa uniformizar o como entendimento dos Estados sobre a temática e efetivar o disposto na Declaração Americana dos Direitos e Deveres do Homem e na Convenção Americana de Direitos Humanos.

\section{OPINIÃO CONSULTIVA DO EQUADOR E INTERPRETAÇÃO EVOLUTIVA DOS DIREITOS HUMANOS}

Em 18 de agosto de 2016 o Equador apresentou a Corte Interamericana com fundamento no artigo 64 da Convenção Americana de Direitos Humanos - Pacto de San José da Costa Rica, cujo objetivo imediato visava à interpretação do artigo 22(7) da Convenção, à luz do asilo enquanto direito humano.

El asilo es una institución de carácter político mediante la cual una persona perseguida por motivos o delitos políticos cuya vida, libertad o integridad física corren peligro dentro de un Estado (denominado territorial), es sustraída de éste por un acto unilateral de otro Estado (denominado asilante), con el fin de evitar la acción coercitiva de los órganos represivos del Estado territorial o la materialización de actos de violencia colectiva contra esta persona ${ }^{34}$.

Mormente intentando esclarecer os seguintes pontos: (i) como deve se tratar o instituto do asilo, em suas diferentes formas, e a legalidade de seu reconhecimento como um direito humano de cada indivíduo, em consonância com o princípio da igualdade e não discriminação? (ii) qual o escopo e propósito do direito de asilo, à luz do Direito Internacional dos Direitos Humanos, Direito Interamericano e Direito Internacional? (iii) qual a natureza e o escopo do instituto do asilo e, para

\footnotetext{
${ }^{32}$ PIOVESAN, Flávia. Direitos humanos e diálogo entre jurisdições. Revista Brasileira de Direito Constitucional - RBDC. n. 19 - jan./jun. 2012 Disponível em: < http://www.esdc.com.br/seer/index.php/rbdc/article/view/176/170 > Acesso em 17 set. 2017. p.89

${ }^{33}$ MAZZUOLI, Valério de Oliveira. Curso de direito internacional público. 9. ed. rev., atual. e ampl. -- São Paulo: Editora Revista dos Tribunais, 2015. p.983.

${ }^{34}$ STEINER, Christian. Convención Americana sobre Derechos Humanos: comentada. Colombia: Fundación Konrad Adenauer, Programa Estado de Derecho para Latinoamérica, 2014. p.514.

Revista de Direito Brasileira | Florianólopis, SC | v. 25 | n. 10 | p. 183-199 | Jan./Abr. 2020
} 
este fim, qual deve ser a interpretação que garante a mais efetiva implementação do artigo 22(7) da Convenção Americana de Direitos Humanos, inclusos os casos de asilo diplomático?

Diante da solicitação de opinião consultiva, a Corte Interamericana de Direitos Humanos, instou os interessados a apresentarem suas considerações sobre os principais pontos da consulta, na figura de amicus curiae, mediante possibilidade constante no artigo 73.3 de seu Regulamento.

A temática envolvendo a consulta é complexa, perpassa o instituto do asilo, o qual para efeitos deste trabalho, se compreende como "la protección que presta un Estado a personas que no son nacionales suyos pero cuya vida, libertad o integridad física corren peligro por amenazas o persecuciones de las autoridades del Estado de procedencia y que, por este motivo, solicitan amparo a las autoridades de otro Estado ${ }^{35}$ ".

O direito de asilo tem suas bases fundadas nos princípios da Declaração Universal dos Direitos do Homem, mormente quando a mesma reconhece ao indivíduo sua dignidade e seus direitos fundamentais inalienáveis, com o fito de promoção da paz mundial, intentando evitar e dirimir o desrespeito aos direitos humanos, a fim de que " os homens gozem de liberdade de palavra, de crença e da liberdade de viverem a salvo do temor e da necessidade ${ }^{36 "}$.

$\mathrm{O}$ instituto vem expresso no artigo 14 do qual se depreende que todo aquele que for vitima de perseguição, tem salvaguardado seu direito de asilo em país em que esteja a salvo, ressalvando que referido direito não pode ser invocado em casos da motivação da perseguição ter origem em crime comum ou ato contrario aos princípios da ONU.

Verifica-se que, embora se trate de instituto cuja finalidade é a proteção da pessoa humana, ainda é considerado por parte da doutrina como um direito de Estado, vez que este não está obrigado a conceder o asilo ${ }^{37}$, o que o difere da figura do refugiado, sendo esta uma decisão política. Conforme se depreende de diversos documentos internacionais a respeito, dentre os quais se destacam a Convenção sobre Asilo de Havana, a Convenção sobre Asilo Político de Montevidéu, a Convenção sobre o Asilo Político de Montevidéu, a Convenção Interamericana sobre Asilo Diplomático de Caracas e outros não menos importantes, mas ora não abordadas.

Há que se ponderar, entretanto - que por tratar-se de direito humano, e estar-se encarandoo em uma necessária interpretação evolutiva dos direitos humanos - o instituto do asilo, não mais diz respeito somente a livre arbitrariedade dos Estados, tendo reflexos diplomáticos e jurídicos de repercussão internacional, "a antiga discricionariedade plena da concessão de asilo passa, agora, por ser um tema de direito internacional, a ser regulada e o Estado pode vir a ser chamado perante um tribunal ${ }^{38, "}$.

Neste sentido, não se pode olvidar das bases históricas de tal afirmação, que remontam ao $1^{\circ}$ Congresso Hispano-Luso-Americano realizado em 1951 em Madri, o qual definiu o direito ao asilo como "um direito inerente à pessoa humana, devendo conceder-lhe o Estado solicitado em virtude da sociabilidade universal de todos os povos ${ }^{39}$ ".

${ }^{35}$ STEINER, Christian. Convención Americana sobre Derechos Humanos: comentada. Colombia: Fundación Konrad Adenauer, Programa Estado de Derecho para Latinoamérica, 2014. p.512.

${ }^{36}$ Declaração Universal dos Direitos do Homem. Disponível em: < http://pfdc.pgr.mpf.mp.br/atuacao-e-conteudos-deapoio/legislacao/direitos-humanos/declar_dir_homem.pdf > Acesso em 04 jul. 2017.

${ }^{37}$ WACHOWICZ, Marcos. O Direito de asilo como expressão dos direitos humanos. Revista da Faculdade de Direito da Universidade Federal do Paraná. 144-156. Disponível em: < revistas.ufpr.br/direito/article/download/1776/1473 > Acesso em 01 jun 2017. p.148.

${ }^{38}$ RAMOS, André de Carvalho. Asilo e refúgio: semelhanças, diferenças e perspectivas. In: RAMOS, A. C; RODRIGUES, G.; ALMEIDA, G. A. (Orgs.). In: 60 anos de ACNUR: perspectivas de futuro. São Paulo: Editora CLA Cultural, 2011, p. 19.

${ }^{39}$ WACHOWICZ, Marcos. O Direito de asilo como expressão dos direitos humanos. Revista da Faculdade de Direito da Universidade Federal do Paraná. 144-156. Disponível em: < revistas.ufpr.br/direito/article/download/1776/1473 > Acesso em 01 jun 2017. p.148.

Revista de Direito Brasileira | Florianólopis, SC | v. 25 | n. 10 | p. 183-199 | Jan./Abr. 2020 
Independentemente da corrente a ser adotada, mister ressaltar o caráter humanitário do instituto, sendo certo que o dever de salvaguarda a vida e a liberdade do indivíduo, deve se sobrepor à questões políticas, em uma interpretação extensiva e evolutiva dos direitos humanos.

O problema de asilo internacional vem a muito tempo chamando a atenção dos juristas, que perceberam a necessidade de sua sistematização em letra convencional, além da sua consagração em direito interno. A tarefa não se tem apresentando fácil, não só em razão de discrepâncias doutrinárias, como sobre tudo da escassa disposição de alguns Estados de realizá-la, por incofessáveis interesses de natureza política e econômica ${ }^{40}$.

É por este motivo, e considerando-se que os direitos humanos são frutos de lutas sociais, uma verdadeira construção ${ }^{41}$, levando-se em consideração que os documentos de direito internacional são sujeitos a "uma interpretação evolutiva, de termos de conteúdo indeterminado, como privacidade, devido processo legal, interesse público, entre outros, que pode variar de acordo com o contexto de cada época ${ }^{42}$ ". Teoria pela qual se compreende que "que o instrumento internacional de direitos humanos deve ser interpretado de acordo com o sistema jurídico do momento de sua aplicação ${ }^{43}$ ".

Nesta toada, mister salientar a presença de referida possibilidade interpretativa nos citados documentos internacionais.

Nesse sentido, a Corte Europeia de Direitos Humanos tem jurisprudência constante que afirma ser a Convenção Europeia de Direitos Humanos um "instrumento vivo", que deve ser interpretado "à luz das condições do presente". Já a Corte Internacional de Justiça decidiu que "um instrumento internacionaldeve ser interpretado e aplicado no âmbito do conjunto do sistema jurídico em vigor no momento em que a interpretação é feita". A Corte Interamericana de Direitos Humanos, por seu turno, adotou esse princípio, sustentando que "la evolución de los tiempos y las condiciones de vida actuales" devem direcionar a interpretação dos diplomas de direitos humanos. Com isso, garante-se a consonância da interpretação internacional das normas de direitos humanos com os novos parâmetros sociais, que afetam a própria determinação do que vem a ser a dignidade da pessoa humana ${ }^{44}$.

Outrossim, importante pontuar o princípio da primazia da norma mais favorável ao indivíduo, que invoca que "nenhuma norma de direitos humanos pode ser invocada para limitar, de qualquer modo, o exercício de qualquer direito ou liberdade já reconhecida por outra norma internacional ou nacional ${ }^{45}$ ", princípio aplicável à temática do asilo discutida na solicitação de opinião consultiva do Equador, vez que há divergências sobre a figura do instituto do asilo e seu caráter humanitário e obrigatório protetivo ao indivíduo, ou seu cunho de decisão política de discricionariedade dos Estados.

A própria Corte Interamericana de Direitos Humanos já reconheceu o princípio citado, tendo o feito inclusive mediante parecer consultivo, em caso de opinião consultiva solicitada pela

${ }^{40}$ CARVALHO, Júlio Marino de. Asilo político e direitos humanos. São Paulo: Forense, 2000. p.234.

${ }^{41}$ BOBBIO, Norberto. A Era dos Direitos. Rio de Janeiro, Editora Campus: 1992. p.25.

${ }^{42}$ RAMOS, André de Carvalho. Teoria geral dos direitos humanos na ordem internacional. 2. ed.São Paulo :

Saraiva, 2012.p.78.

${ }^{43}$ RAMOS, André de Carvalho. Teoria geral dos direitos humanos na ordem internacional. 2. ed.São Paulo : Saraiva, 2012.p.78.

${ }^{44}$ RAMOS, André de Carvalho. Teoria geral dos direitos humanos na ordem internacional. 2. ed.São Paulo : Saraiva, 2012.p.78.

${ }^{45}$ RAMOS, André de Carvalho. Teoria geral dos direitos humanos na ordem internacional. 2. ed.São Paulo : Saraiva, 2012.p.80.

Revista de Direito Brasileira | Florianólopis, SC | v. 25 | n. 10 | p. 183-199 | Jan./Abr. 2020 
Costa Rica, que discutia a necessidade de afiliação à Associação de Jornalistas, no qual a CIDH manifestou-se pela interpretação evolutiva e aplicação do princípio da norma mais favorável: "em consecuencia, si a una misma situación son aplicables al Convención Americana y otro tratado internacional, debe prevalecer la norma más favorable a la persona humana ${ }^{46}$ ".

Não obstante todos os conflitos doutrinários e jurisprudenciais envolvendo o direito ao asilo, verifica-se que a solicitação de opinião consultiva requerida pelo Equador perpassa a matéria fática da peculiar questão envolvendo Julian Paul Assange.

A concessão do asilo diplomático por parte do governo equatoriano foi divulgada no dia 15 de agosto de 2012, aceitando o argumento de fundada perseguição política. Por outro lado, o governo britânico rejeitou o ato do país sul-americano e argumentou que tem a obrigação jurídica de cumprir a decisão favorável de extradição ao governo requerente, a Suécia, para que, no país nórdico, o australiano responda as acusações de violência sexual Não obstante toda a controvérsia jurídica e política envolvendo a figura pública de Julian Assange, a concessão do asilo pelo Estado do Equador também foi alvo de discussões ${ }^{47}$.

Verdadeiro incidente diplomático que envolve Estados Unidos, Suécia e Inglaterra, além do próprio Equador, sob o qual Assange se encontra na condição de asilado político na Embaixada do Equador em Londres.

Na ocasião da concessão do asilo, a Organização dos Estados Americanos, doravante denominada de OEA, manifestou-se a favor da decisão do Equador, sem deixar de enfatizar a importância da via diplomática, expressando sua solidariedade. Mais especificamente, a OEA reuniu-se com países em 23 de agosto de 2012, para discutir a situação entre Equador e Reino Unido, com base nos ditames internacionais, a exemplo maior da Convenção de Viena sobre Relações Diplomáticas, de 1961, e da Convenção de Viena sobre Relações Consulares $^{48}$.

Verifica-se que a solicitação de opinião consultiva foi requerida em um momento de transição política no Equador, que ao apresentar a solicitação estava em vias de passar por eleições presidenciais, o que poderia alterar o rumo do asilo diplomático concedido, eis que dependente somente de vontade política.

À luz do caso Assange e sua presença na missão diplomática equatoriana em Londres, o obstáculo ao cumprimento do mandado de prisão pela polícia metropolitana londrina é a imunidade diplomática da embaixada, garantida pela Convenção de Viena, de que tanto Equador como o Reino Unido são partes. Conforme o artigo 22: 1. Os locais da Missão são invioláveis. Os agentes do Estado acreditado não poderão neles penetrar sem o consentimento do Chefe da Missão. 2. O Estado acreditado tem a obrigação especial de adotar todas as medidas apropriadas para proteger os locais da Missão contra qualquer instrução

\footnotetext{
${ }^{46}$ Corte Interamericana de Direitos Humanos, Parecer Consultivo sobre a filiação obrigatória de jornalistas (artigos 13 e 29 da Convenção Americana de Direitos Humanos), Parecer n. 5 de 13 de novembro de 1985, Série A, n. 5, parágrafo 52 , p. 31.

${ }^{47}$ SILVA, Alexandre Pereira da. O Caso Do Asilo Diplomático De Julian Assange: Três Anos Depois. Revista da Faculdade de Direito-RFD-UERJ - Rio de Janeiro, n. 30 , dez. 2016. Disponível em: < www.epublicacoes.uerj.br/index.php/rfduerj/article/download/18388/19259> Acesso em 05 jun. 2017 p. 37.p. 37.

${ }^{48}$ Corte Interamericana de Direitos Humanos. Solicitação de opiniões consultivas. Equador. Amicus Curiae apresentado por Docentes e pesquisadores da Pontifícia Universidade Católica do Paraná, Centro Universitário $\begin{array}{lllllll}\text { Autônomo } & \text { do } & \text { Brasil } & \text { e } & \text { Faculdade } & \text { Campo } & \text { Real. }\end{array}$ http://www.corteidh.or.cr/sitios/observaciones/oc25/41_docentes_otros.pdf > Acesso em 17 jun. 2017.
}

Revista de Direito Brasileira | Florianólopis, SC | v. 25 | n. 10 | p. 183-199 | Jan./Abr. 2020 
ou dano e evitar perturbações à tranquilidade da Missão ou ofensas à sua dignidade ${ }^{49}$.

Decidido em segundo turno, o processo eleitoral terminou com a vitória de Lenín Moreno, que venceu em uma disputa acirrada o candidato Guillermo Lasso que havia anunciado seu desejo de retirar o benefício concedido a Assange, que permanece na Embaixada.

\section{CONSIDERAÇÕES FINAIS}

Com a modificação do enfrentamento às questões atinentes aos direitos humanos, mormente no período do pós-segunda guerra, e seu consequente e irreversível processo de internacionalização, os organismos internacionais passaram a se ocupar diretamente com as referidas questões.

Não poderia ser diferente no âmbito da Organização dos Estados Americanos. Seu sistema de proteção aos direitos humanos, consistente em atuação consultiva e contenciosa, tem demonstrado o quão atuante seu órgão máximo tem sido perante as questões de violação ou ameaça de lesão aos direitos humanos dos países afiliados.

A função interpretativa e de orientação da Corte, representada pela sua atuação consultiva, mediante as solicitações de opiniões consultivas pelos países membros, demonstrou-se pelo estudo realizado, um poderoso instrumento de uniformização de entendimentos no que tange a interpretação dos direitos humanos nas Américas.

Não se pode olvidar, que ao se falar em direitos humanos no/do/para as Américas, é mister ressaltar o movimento descolonialista e sua interpretação sobre os direitos humanos, abordada brevemente no texto. Foi com este viés que o presente artigo buscou analisar a questão da jurisdição consultiva da Corte Interamericana de Direitos Humanos em sua atuação consultiva, tomando por base uma visão descolonialista, demonstrando a evolução interpretativa dos direitos humanos, mormente do conceito de asilo, que embasou a atuação do órgão na solicitação de opinião consultiva do Equador.

A discussão sobre a natureza do direito de asilo, enquanto direito humano, e para parte da doutrina, verdadeiro direito humanitário, a questão da interpretação do texto legal pelo princípio da norma mais favorável, e a crescente atuação do órgão, galgada nos movimentos descolonialistas, demonstraram que a Corte, tem, cada vez mais, utilizado de mecanismo interpretativos em sua atuação consultiva, para defender uma visão evolutiva dos direitos humanos, embasada em uma visão descolonialista dos referidos direitos, buscando adequar o positivado à realidade latinoamericana.

Por fim, vale a pena destacar a necessidade de se compreender a importância dos juízes nacionais em aplicarem corretamente os tratados de direitos humanos dentro das suas jurisdições. Trata-se, portanto, de se efetivar o controle de convencionalidade dos tratados de direitos humanos e de forma a honrar o cumprimento das normas internacionais e que foram devidamente ratificadas.

\section{REFERÊNCIAS}

\section{BAPTISTELA, Tiago. A integração e a convergência do asilo e do refugio na Declaração de} Cartagena. (mestrado em direito) Santa Maria, 2016.

\footnotetext{
${ }^{49}$ SILVA, Alexandre Pereira da. O Caso Do Asilo Diplomático De Julian Assange: Três Anos Depois. Revista da Faculdade de Direito-RFD-UERJ - Rio de Janeiro, n. 30, dez. 2016. Disponível em: < www.epublicacoes.uerj.br/index.php/rfduerj/article/download/18388/19259> Acesso em 05 jun. 2017 p. 46.

Revista de Direito Brasileira | Florianólopis, SC | v. 25 | n. 10 | p. 183-199 | Jan./Abr. 2020
} 
BRASIL. Justiça e Segurança Pública. Disponível em: < http://www.justica.gov.br/noticias/entenda-as-diferencas-entre-refugio-e-asilo > Acesso em 01 set. 2017.

BOBBIO, Norberto. A Era dos Direitos. Rio de Janeiro, Editora Campus: 1992.

CARVAlHO, Júlio Marino de. Asilo político e direitos humanos. São Paulo: Forense, 2000.

CORTE INTERAMERICANA DE DIREITOS HUMANOS. Solicitud de Opinión Consultiva presentada por el Estado del Ecuador ante la Corte Interamericana de Derechos Humanos. Disponível em:〈http://www.corteidh.or.cr/docs/solicitudoc/solicitud_18_08_16_esp.pdf > Acesso em 01 jul. 2017.

CORTE INTERAMERICANA DE DIREITOS HUMANOS. Solicitação de opiniões consultivas. Equador. Amicus Curiae apresentado por Docentes e pesquisadores da Pontifícia Universidade Católica do Paraná, Centro Universitário Autônomo do Brasil e Faculdade Campo $\underline{\text { Real. }}$ < http://www.corteidh.or.cr/sitios/observaciones/oc25/41_docentes_otros.pdf > Acesso em 17 jun. 2017.

CORTE INTERAMERICANA DE DIREITOS HUMANOS. Parecer Consultivo sobre a filiação obrigatória de jornalistas (artigos 13 e 29 da Convenção Americana de Direitos Humanos), Parecer n. 5 de 13 de novembro de 1985, Série A, n. 5, parágrafo 52.

CORTE INTERAMERICANA DE DIREITOS HUMANOS. Parecer consultivo solicitado pelo Peru - Opinião Consutiva 1, de 24 de setembro de 1982. Disponível em: < http://www.corteidh.or.cr/cf/Jurisprudencia2/solicitud_opiniones_consultivas.cfm?lang=es > Aceso em 07 jul. 2017

DUSSEL, Enrique. Europa, modernidade e eurocentrismo. In: LANDER, Edgardo. A colonialidade do saber: eurocentrismo e ciências sociais. Perspectivas latino-americanas. Colección Sur Sur. CLACSO: Buenos Aires: 2005.

JAYME, Fernando G. Direitos Humanos e sua efetivação pela Corte Interamericana de Direitos Humanos. Belo Horizonte: Del Rey, 2005.

MAZZUOLI, Valério de Oliveira. Curso de direito internacional público. 9. ed. rev., atual. e ampl. -- São Paulo: Editora Revista dos Tribunais, 2015.

MAZZUOLI, Valério de Oliveira. Curso de direitos humanos. 9. ed. rev., atual. e ampl. São Paulo: Método, 2014.

OLIVEIRA, Assis da Costa. Pós-Colonialismo, Relações Internacionais E Direitos Humanos: Análise Do Caso Mayagna (Sumo) Awas Tingni Vs. Estado Da Nicarágua. O Direito Alternativo, v.2, n.1, pp. 39-63, junho de 2013.

ONU. Organização das Nações Unidas . Carta da ONU. <

http://unicrio.org.br/img/CartadaONU_VersoInternet.pdf > Acesso em 15 jun. 2017. 
ONU. Declaração Universal dos Direitos do Homem. Disponível em: < http://pfdc.pgr.mpf.mp.br/atuacao-e-conteudos-de-apoio/legislacao/direitoshumanos/declar_dir_homem.pdf > Acesso em 04 jul. 2017.

PIOVESAN, Flávia. Direitos Humanos e Justiça Internacional. São Paulo: Saraiva, 2006. p. 99.

PIOVESAN, Flávia. Direitos humanos e diálogo entre jurisdições. Revista Brasileira de Direito Constitucional - RBDC. n. 19 - jan./jun. 2012 Disponível em: < http://www.esdc.com.br/seer/index.php/rbdc/article/view/176/170 > Acesso em 17 set. 2017.

QUIJANO, Anibal. Colonialidade do poder, Eurocentrismo e América Latina. In.: A colonialidade do saber: eurocentrismo e ciências sociais. Perspectivas latinoamericanasCLACSO, Consejo Latinoamericano de Ciencias Sociales, Buenos Aires: 2005.

RAMOS, André de Carvalho. Asilo e refúgio: semelhanças, diferenças e perspectivas. In:

RAMOS, A. C; RODRIGUES, G.; ALMEIDA, G. A. (Orgs.). In: 60 anos de ACNUR: perspectivas de futuro. São Paulo: Editora CL-A Cultural, 2011, p. 19.

RAMOS, André de Carvalho. Teoria geral dos direitos humanos na ordem internacional. 2. ed. São Paulo : Saraiva, 2012.p.78.

ROA ROA, Jorge Ernesto. La aplicación nacional de la jurisprudencia de la Corte Interamericana sobre derechos políticos. Serie Documentos de Trabajo n. ${ }^{\circ} 37$, Departamento de Derecho Constitucional, pp. 1-32. Colombia: Universidade Externado.

SANTOS, Alberto da Silva. O Sistema Interamericano de proteção aos Direitos Humanos e a soberania Estatal. Dissertação de Mestrado. PUCPR, 2010.

SANTOS, Boaventura de Sousa. Descolonizar el saber, reinventar el poder. Ediciones Trilce, Montevidéu: 1988.

SANTOS, Boaventura de Sousa. Para além do pensamento abissal: das linhas globais a uma ecologia de saberes. Novos Estudos, n. 79. 2007. Disponível em: < http://www. scielo.br/pdf/nec/n79/04.pdf > Acesso em 12 jul. 2017.

SILVA, Alexandre Pereira da. O Caso Do Asilo Diplomático De Julian Assange: Três Anos Depois. Revista da Faculdade de Direito-RFD-UERJ - Rio de Janeiro, n. 30, dez. 2016. Disponível em: < www.e-publicacoes.uerj.br/index.php/rfduerj/article/download/18388/19259> Acesso em 05 jun. 2017 p. 37.

STEINER, Christian. Convención Americana sobre Derechos Humanos: comentada.

Colombia: Fundación Konrad Adenauer, Programa Estado de Derecho para Latinoamérica, 2014.

STRELHOW, Thyeles Moratti Precilio Borcarte . Direitos humanos: reflexões por um processo de descolonização. Revista Interdisciplinar de Direitos Humanos. Bauru, v. 4, n. 2, p. 59-76, jul./dez., 2016 (7). Disponível em: < http://www2.faac.unesp.br/ridh/index.php/ridh/article/view/389 > Acesso em 25 jun. 2017. 